\title{
OPTICAL EVALUATION OF CORROSION PRODUCTS USING COLORIMETRIC SPECTROSCOPY
}

\author{
${ }^{1}$ Dušan MAJTÁS, ²Pavlína FIALOVÁ \\ ${ }^{1}$ The Czech Academy of Sciences, Institute of Theoretical and Applied Mechanics, Prague, \\ Czech Republic, EU, majtas@itam.cas.cz \\ ${ }^{2}$ SVUOM Itd., Prague, Czech Republic, EU \\ https://doi.org/10.37904/metal.2019.951
}

\begin{abstract}
Aim of this work is to test possibility to utilize colorimetric spectroscopy for monitoring the corrosion of lead and tin-lead alloys. And furthermore method suitability for preliminary corrosion evaluation of cultural heritage objects. According to literature colorimetry is used to monitor patinas of bronze objects, thus the method might be also suitable for lead based alloys. Samples used were made from commercially produced lead plate. These were exposed in the climatic chamber to different relative humidity $(60,80,90 \%)$. After the exposure the corrosion products with different color formed on sample surface. These corrosion products were evaluated by different methods: optical microscopy, colorimetric spectroscopy, and X-ray chemical analysis. Collected colorimetric data display difference between treatments suitable for patina evolution monitoring. The paper presents obtained results and comparison of applied methods.
\end{abstract}

Keywords: Corrosion, lead, cultural heritage, laboratory simulation, colorimetry, spectroscopy, optical method

\section{INTRODUCTION}

Conservators and museum and collection curators need method to evaluate degradation of the objects held in collection. Commonly used analytical methods to evaluate patinas and corrosion products consists of microscopy (both optical and scanning electron microscopy), Raman spectroscopy, Fourier transformation infrared spectroscopy, x-ray diffraction [1-4]. These techniques are capable to analyze phase composition and crystalline structure of the corrosion products.

Technical problems may arise when dealing with objects of cultural heritage. Some instruments may be unsuitable due to the relatively small workspace of the instrument compared to the size of the object examined. Another choke point might be complex geometry of the object, which might be small enough to go inside but collide with instrument and sensors. Such situation may be limiting but it is still possible to use handheld instrument such as portable spectrocolorimeter. With portable instrument in situ measurements to evaluate state of patina and surface could be done. Drawback is that spectrocolorimeter could not produce phase identification.

Colorimetric techniques are used to analyze artworks, paintings or building materials $[5,6]$, but could be also employed to analyze metal coatings or metallic objects [4,7-13]. According to the industrial usage on highly reflective surfaces to avoid light-dark flop effect spectrocolorimeter capable of multi-angular measurement on the surface should be used [14]. However usage of spectrocolorimeter with $10^{\circ}$ observer configuration and D65 was encountered in various articles $[4,7,8,12,13]$. Better option would be to collect reflectance spectra alongside the color information.

According to [15] Lead corrosion products are mainly white $\left(\mathrm{PbO}_{2}, \mathrm{PbCl}, \mathrm{PbCO}_{3}, \mathrm{~Pb}_{3}\left(\mathrm{CO}_{3}\right)_{2}\right.$ and $\left.\mathrm{PbSO}_{4}\right)$; additional corrosion products are red $\left(\mathrm{Pb}_{3} \mathrm{O}_{4}\right)$ and black $(\mathrm{PbS})$. Tin corrosion products are mainly black ( $\mathrm{SnO}$ and $\left.\mathrm{SnO}_{2}\right)$; additional corrosion products are yellow $\left(\mathrm{SnS}_{2}\right)$ and brown $(\mathrm{SnS})$. 
The question to be answered: is it is possible to evaluate corrosion of lead and tin-lead alloys utilize colorimetric spectroscopy for monitoring the corrosion of lead and tin-lead alloys? And furthermore if it is suitable for preliminary evaluate corrosion and its progress?

\section{METHODICS}

The optical evaluation would consist of optical microscopy using low magnification stereomicroscope, high magnification $3 \mathrm{~d}$ optical microscope and spectrocolorimeter. The optical evaluation of the surface using optical microscopes should back up the results of the colorimetry.

Chemical composition of the alloy of the objects will be determined by X-ray fluorescence spectroscopy (XRF) method. Samples used in this article are made of commercially obtained Lead sheet composition of which has been analyzed by XRF is described in the Table 1.

Table 1 Chemical composition of the alloy analyzed by XRF

\begin{tabular}{|c|c|c|c|c|c|}
\hline Element & Pb & Sn & Ga & Zn & Cu \\
\hline Average (wt\%) & $95.98 \pm 0.02$ & $2.4 \pm 0.15$ & $0.18 \pm 0.01$ & $0.03 \pm 0.01$ & $0.03 \pm 0.01$ \\
\hline
\end{tabular}

\subsection{Sample preparation}

Samples used in this work were prepared from lead sheet. Sample geometry was coupon $80 \mathrm{~mm} \times 30 \mathrm{~mm}$ (height and width) and thickness of $1 \mathrm{~mm}$ (thickness of the lead sheet used). Coupons were measured and weighted. Prior the artificial ageing the pre-existent corrosion layer was removed using Chelaton III according to literature [16-19]. Then the samples were put into the climatic chamber under the specified conditions and underwent the test treatment (exposition).

Lead sheet used in coupon preparation was not polished to simulate non-ideal surface of objects. Accelerated ageing in the climatic chamber is also producing patina that would not be homogeneous compared to patina formed during long term exposure to the environment. Surface where colorimetric spectra will be measured have to be flat without macroscopic deformities or curvatures, but that surface need not be ideally flat. Other problematic part may be over-reflectivity of clean surface with corrosion products removed [14]. Reflectance spectra will be also collected for each measurement point (both color information and reflectance spectra).

\subsection{Climatic chamber test}

For the artificial ageing, the climatic chambers CTS C-40/200 and CTS C+10/600-SG were used. The SG chamber was put into the climatic regime by removing the artificial atmosphere box. In the first step the samples should be treated under constant conditions, where all of the conditions except of relative humidity should remain constant for the all test, while the different sets of samples will be treated under different relative humidity conditions. Conditions in the climatic chamber were kept constant for test duration and filed. Temperature used in the chamber was $23^{\circ} \mathrm{C}$ for all the test. Relative humidity settings covered by this work were 60,80 and $90 \%$.

The length of the test was 2 months ( 60 days). Reason for such length of the test was to specify corrosion rate by mass loss. However using standard laboratory balance of four decimal places, no measurable difference in weight could be found and thus the mass loss measurement was omitted. To maintain comparability all tests were running for 2 months. There is a plan for upcoming tests to analyze the samples after 1 month and then after the 2 months to decrease the test length if possible.

\subsection{Optical analysis}

After the climatic chamber treatment all samples were photo documented. Surface was examined under the optical microscope Olympus SZX7 under magnification $2 \times$. In addition surface was also viewed under the 
polarized light using HIROX KH-7700 optical 3D microscope and magnification from $200 \times$ to $600 \times$. Surface reconstruction using 3D scan was also performed, but due to the minimal height difference caused by the corrosion process could not produce any suitable information further.

Spectrocolorimetry was conducted afterwards. The colorimetry is based on a set of standards defined by Commision Internationale de l'Eclairage (CIE) [20-24]. These standards define color space which is mathematic relation between distribution of visible spectrum wavelengths, and human color vision. CIEXZY color space was created by International Commission on Illumination in 1931 [25]. However for practical use color space not directly based on red-green-blue color information but rather hue-chroma-lightness or lightness and 2-axis color ratio might be more suitable.

The CIELHC color space where the hue $\left(\mathrm{h}^{\circ}\right)$ is how we perceive an object so the color quality, the chroma $\left(C^{*}\right)$ describes the vividness or dullness of a color, in other words how close the color is to gray or to the pure hue, and the lightness $\left(L^{*}\right)$ is the luminous intensity of a color. [20-24,26].

The color ratio based CIELAB color space where red/green ration $\left(a^{*}\right)$ is positive in the red region, negative in the green region, blue/yellow ration $\left(b^{*}\right)$ is positive in the yellow region and negative in the blue region and the lightness $\left(L^{*}\right)$ is the luminous intensity $[23,26,27]$.

Avantes StarLine AvaSpec-2048 spectrocolorimeter (light source D65, 10 standard observer), with AvaSoft 8.0 processing software was used. For each sample six separate measurements have been utilized (on six different locations of the sample surface). For each measurement color information in CIELAB, CIELCH and CIEXYZ color space has been obtained alongside with reflectance spectra. Both reflectance spectra and color space coordinates were collected [28,29]. Data were collected for all coupons on all six spots per coupon.

Reason why the color change $\Delta \mathrm{E}$ has not been used in this research is that samples prepared and analyzed are not in the continuous time line of corrosion/patina evolution, but of different conditions under which the patina had been created. The $\Delta \mathrm{E}$ is scalar value but vector value is more suitable to describe difference between treatments.

\section{RESULTS}

Samples observed by naked eye displays following: samples treated under $60 \%$ relative humidity are darker colored compared to samples treated under $80 \%$ relative humidity. Samples treated under $90 \%$ relative humidity look similar to untreated samples. During the initial phase of the treatment goldish tint was observed on the sample surface to form. This goldish tint developed earlier during the treatment approx. 7 to 14 days from the beginning of the artificial ageing and faded continually not to be visible by naked eye.

\subsection{Optical analysis - Microscope Olympus}

Using optical microscope Olympus SXZ 7, the surface difference could be observed between samples without treatment and the samples after the treatment. Under same lighting conditions samples without treatment are lighter than samples after the treatment with wide contrast difference (Figure 1). The untreated surface displays scratches both produced during manufacturing process and during sample preparation. Degradation of the surface caused by artificial ageing is resulting surface roughness change. Scratches are less visible, but the corrosion is non-uniform.

Visibility of surface scratches is decreasing in sequence form $90 \%$ to $60 \%$ relative humidity treatment. Nonuniform corrosion is most significant under $80 \%$ relative humidity treatment than under $60 \%$ relative humidity treatment. This suggests corrosion is not linear function of humidity, for lead coupons under $23^{\circ} \mathrm{C}$ and there is some peak where environment is most corrosive. Further research is needed to prove and describe. 

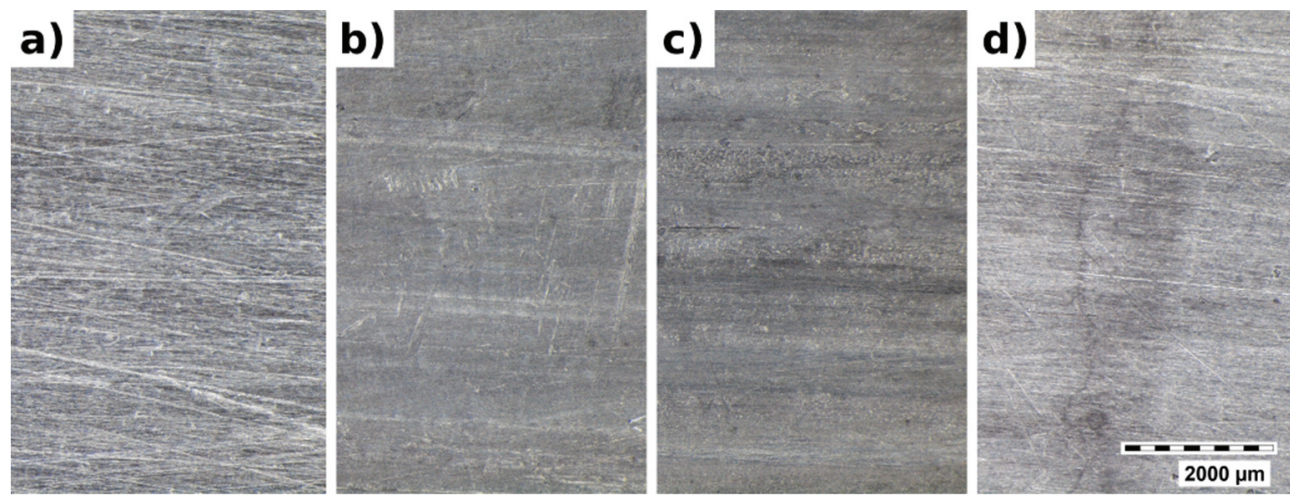

Figure 1 Optical microscopy of samples using Olympus SXZ7 microscope: non-polarized light: a) untreated, b) $60 \%$, c) $80 \%$, d) $90 \%$ relative humidity

\subsection{Optical analysis - Microscope HIROX}

Using optical microscope of higher magnification, where polarized light has been used displays further differences. The surface and patina observed is shown on Figure 2. Corrosion of the surface is not uniform. On the samples prepared under the $80 \%$ relative humidity height difference could be observed. Samples prepared under $60 \%$ relative humidity treatment have significantly lower height difference, but under the polarized light displays color structures. These color structures are probably corresponding to the grain structure of the material.
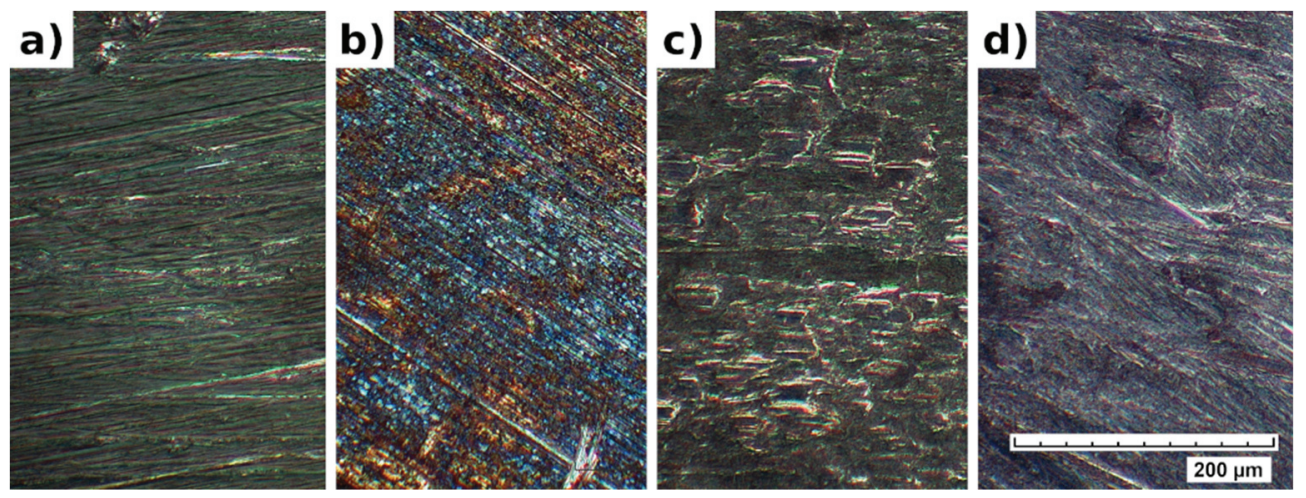

Figure 2 Optical microscopy of samples using HIROX KH-7700 3D optical microscope, used polarized light: a) untreated, b) $60 \%$, c) $80 \%$, d) $90 \%$ relative humidity

According to the state of the surface non-uniform corrosion observed is most significant on the samples under the $80 \%$ relative humidity treatment, preferring orientation of grains to propagate. Under the $60 \%$ relative humidity the corrosion propagates more uniformly. The surface roughness produced by corrosion will affect colorimetric measurement [14]. Next logical step would be phase identification of the corrosion product that also affects color $[15,18]$.

\subsection{Optical analysis - Colorimetric spectroscopy}

Using colorimetric spectroscopy the samples shows difference in both surface color and reflectance of the surface in the Table 2 and Table 3. This is in agreement with previous optical evaluation of the samples. Compared to the results of other colorimetric measurement (despite different material used) [7-13] the deviation between the measurements on coupons that underwent same treatment or between the measurement on the surface of coupon is rather high (Table 4 and Table 5). The wide interval is caused by the surface conditions and relatively short time for the patina to produce and the configuration of the color 
measurement [14]. But even under such conditions the colorimetric measurement could be used to distinguish between different artificial ageing conditions.

Table 2 Color values of non-treated samples measured on samples in CIELAB space

\begin{tabular}{|c|c|c|c|c|c|}
\hline \multirow{2}{*}{} & \multicolumn{5}{|c|}{ Non-treated } \\
\cline { 2 - 6 } & P16 & P17 & P18 & P19 & P20 \\
\hline L & 84 & 74 & 79 & 87 & 75 \\
\hline a & 3 & 3 & 3 & 3 & 3 \\
\hline b & -4 & -1 & -2 & -5 & -2 \\
\hline
\end{tabular}

Table 3 Color values of samples grouped per treatment measured on samples in CIELAB space

\begin{tabular}{|c|c|c|c|c|c|c|c|c|c|c|c|c|c|c|c|}
\hline & \multicolumn{15}{|c|}{ Treatment - relative humidity } \\
\hline & \multicolumn{5}{|c|}{$60 \%$} & \multicolumn{5}{|c|}{$80 \%$} & \multicolumn{5}{|c|}{$90 \%$} \\
\hline & P06 & P07 & P08 & P09 & P10 & P01 & $\mathrm{P} 02$ & P03 & P04 & P05 & P11 & P12 & P13 & P14 & P15 \\
\hline $\mathrm{L}$ & 44 & 38 & 49 & 47 & 49 & 67 & 66 & 69 & 67 & 61 & 74 & 72 & 75 & 75 & 75 \\
\hline a & 2 & 2 & -3 & 0 & -2 & -11 & -11 & -11 & -11 & -9 & 3 & 4 & 4 & 4 & 5 \\
\hline$b$ & 62 & 59 & 59 & 63 & 63 & 42 & 43 & 41 & 41 & 49 & -2 & -5 & -4 & -5 & -6 \\
\hline
\end{tabular}

Table 4 Standard deviations of the CIELAB color space values, non-treated samples

\begin{tabular}{|c|c|c|c|c|c|}
\hline \multirow{2}{*}{} & \multicolumn{5}{|c|}{ Non-treated } \\
\cline { 2 - 6 } & P16 & P17 & P18 & P19 & P20 \\
\hline oL & 1.51 & 2.19 & 5.28 & 1.89 & 3.77 \\
\hline oa & 0.19 & 0.14 & 0.16 & 0.23 & 0.19 \\
\hline ob & 0.5 & 0.04 & 1.1 & 0.73 & 0.73 \\
\hline
\end{tabular}

Table 5 Standard deviations of the CIELAB color space values, per treatment measured on samples

\begin{tabular}{|c|c|c|c|c|c|c|c|c|c|c|c|c|c|c|c|}
\hline & \multicolumn{15}{|c|}{ Treatment - relative humidity } \\
\hline & \multicolumn{5}{|c|}{$60 \%$} & \multicolumn{6}{|c|}{$80 \%$} & \multicolumn{4}{|c|}{$90 \%$} \\
\hline & P06 & P07 & P08 & P09 & P10 & P01 & P02 & P03 & P04 & P05 & P11 & P12 & P13 & P14 & P15 \\
\hline$\sigma \mathrm{L}$ & 2.18 & 6.62 & 6.01 & 5.96 & 5.64 & 2.91 & 4.16 & 3.31 & 4.74 & 3.1 & 1.24 & 4.81 & 3.74 & 2.6 & 7.83 \\
\hline бa & 1.81 & 1.63 & 4.01 & 2.74 & 1.73 & 0.3 & 0.32 & 0.31 & 0.53 & 0.72 & 0.41 & 0.32 & 0.31 & 0.28 & 0.72 \\
\hline$\sigma b$ & 1.07 & 0.22 & 4.57 & 2.19 & 3.62 & 2.28 & 4.43 & 3.57 & 4.79 & 2.48 & 0.95 & 1.35 & 0.54 & 0.48 & 1.36 \\
\hline
\end{tabular}

Using only CIELAB space colorimetry can be used to distinguish between samples untreated, $60 \%$ and $80 \%$ relative humidity, but may not be suitable to distinguish between untreated samples and samples treated under $90 \%$ relative humidity. According to the surface analysis corrosion under the $90 \%$ relative humidity propagates with slower rate.

Table 6 represents the color information obtained using both CIELHC and CIEXYZ color space. The color information were obtained in the same measurement as the previously discussed CIELAB color space coordinates, under same measurement and light conditions, collected at same measuring spots. Coupons treated under $90 \%$ relative humidity displayed less scattered results in CIEXYZ color space (with the exception of sample $P$ 15) than non-treated samples. Standard deviations for these measurements are shown in Table 7. 
Table 6 Color values of non-treated samples and under $90 \%$ relative humidity artificial ageing treatment measured in CIELHC and CIEXYZ space

\begin{tabular}{|l|c|c|c|c|c|c|c|c|c|c|}
\hline & \multicolumn{4}{|c}{ Non-treated } & \multicolumn{5}{c|}{ 90 \% relative humidity } \\
\cline { 2 - 15 } & P16 & P17 & P18 & P19 & P20 & P11 & P12 & P13 & P14 & P15 \\
\hline L & 84 & 74 & 79 & 87 & 75 & 74 & 72 & 75 & 75 & 75 \\
\hline $\mathrm{h}$ & 307 & 344 & 327 & 302 & 329 & 329 & 308 & 311 & 308 & 308 \\
\hline $\mathrm{C}$ & 5 & 4 & 4 & 6 & 4 & 4 & 6 & 6 & 6 & 8 \\
\hline $\mathrm{X}$ & 63 & 46 & 54 & 67 & 47 & 46 & 43 & 48 & 48 & 38 \\
\hline $\mathrm{Y}$ & 65 & 48 & 56 & 69 & 48 & 47 & 44 & 49 & 49 & 39 \\
\hline $\mathrm{Z}$ & 76 & 53 & 63 & 86 & 54 & 53 & 53 & 58 & 58 & 47 \\
\hline
\end{tabular}

Table 7 Standard deviations of non-treated samples and under $90 \%$ relative humidity artificial ageing treatment measured in CIELHC and CIEXYZ space

\begin{tabular}{|l|c|c|c|c|c|c|c|c|c|c|}
\hline & \multicolumn{4}{|c|}{ Non-treated } & \multicolumn{5}{c|}{90 \% relative humidity } \\
\cline { 2 - 14 } & P16 & P17 & P18 & P19 & P20 & P11 & P12 & P13 & P14 & P15 \\
\hline$\sigma \mathrm{L}$ & 1.51 & 2.19 & 5.28 & 1.89 & 3.77 & 1.24 & 4.81 & 3.74 & 2.6 & 7.83 \\
\hline$\sigma \mathrm{h}$ & 2.66 & 11.62 & 14.22 & 2.43 & 10.46 & 14.17 & 6.78 & 5.52 & 2.66 & 3.94 \\
\hline$\sigma \mathrm{C}$ & 0.49 & 0.37 & 0.64 & 0.72 & 0.35 & 0.33 & 1.19 & 0.3 & 0.47 & 1.45 \\
\hline$\sigma \mathrm{X}$ & 2.84 & 3.38 & 5.28 & 3.79 & 5.73 & 1.79 & 6.65 & 5.77 & 3.99 & 10.31 \\
\hline$\sigma \mathrm{Y}$ & 2.95 & 3.46 & 5.52 & 3.87 & 5.99 & 1.93 & 6.96 & 6.04 & 4.3 & 10.73 \\
\hline$\sigma \mathrm{Z}$ & 3.88 & 4.11 & 7.25 & 5.45 & 7.44 & 1.35 & 7.49 & 7.46 & 4.57 & 11.82 \\
\hline
\end{tabular}

Assuming from color representation in CIEXYZ color space, CIEXYZ might be better option to describe the surface color state although is not so intuitive and human readable as CIELAB or CIELHC color space. Combining other techniques with spectrocolorimetry can provide information on the corrosion of the surface. On the other hand, if the corrosion product distribution on the surface is less uniform and patina is not well developed the colorimetry may not be suitable.

\section{CONCLUSION}

The results represented in CIELAB color space does provide some information on the state of surface. It can be used to analyze corrosion or patina. It is questionable if usage of CIELHC or CIEXYZ color space instead of CIELAB color space may not be better option, this need further research to approve. The colorimetric measurement could be used as preliminary evaluation method on lead or lead based alloy in combination with other methods. Depending on the state of surface larger number of measurements per object should be collected. Optical microscopy is suitable method to use in combination with colorimetry.

\section{ACKNOWLEDGEMENTS}

This paper has been prepared in scope of NAKI DG18P020VV050 project, Ministry of Culture of Czech Republic.

\section{REFERENCES}

[1] QAFSAOUI, W., TAOUIL, A. ET, KENDIG, M. W., HEINTZ, O., CACHET, H., JOIRET, S. and TAKENOUT, H. Corrosion protection of bronze using 2,5-dimercapto-1,3,4-thiadiazole as organic inhibitor: spectroscopic and electrochemical investigations. Journal of Applied Electrochemistry. 2019. vol. 49, pp. 823-837. 
[2] INGO, G. M., RICCUCCI, C., GIULIANI C., FAUSTOFERRI, A., PIERIGĖ, I., FIERRO, G., PASCUCCI, M., ALBINI M. and CARLO, G.DI. Surface studies of patinas and metallurgical features of uncommon high-tin bronze artefacts from the Italic necropolises of ancient Abruzzo (Central Italy). Applied Surface Science. 2019. vol. 470, pp. 74-83.

[3] FABRIZI, L., TURO, F. DI, MEDEGHINI, L., FAZIO, M. DI, CATALLI, F. and VITO, C. DE. The application of nondestructive techniques for the study of Corrosion patinas of ten Roman silver coins: The case of the medieval Grosso Romanino. Microchemical Journal. 2019. vol. 145, pp. 419-427.

[4] MASI, G., JOSSE, C., ESVAN, J., CHIAVARI, C., BERNARDI, E., MARTINI, C., BIGNOZZI, M. C., MONTICELLI, C., ZANOTTO, F., BALBO, A., SVARA FABJAN, E., KOSEC, T. and ROBBIOLA, L. Evaluation of the protectiveness of an organosilane coating on patinated Cu-Si-Mn bronze for contemporary art. Progress in Organic Coatings. 2019. vol. 127, pp. 286-299.

[5] VALACH, J., BRYSCEJN, J., DRDÁCKÝ, M., SLÍŽKOVÁ, Z. and VAVŘíK, D. Public perception and optical characterization of degraded historic stone and mortar surfaces. In: Fort, R., ALVAREZ de BUERGO, A., GOMEZ-HERAS, J. and VAZQUEZ-CALVO, V., eds. Proceedings of the International Conference on Heritage, Weathering and Conservation, HWC-2006, 21-24 June 2006. Madrid, Spain. Case studies. London: Taylor\&Francis Group. 2006. p. 827-832.

[6] SARICI, D. E. Thermal deterioration of marbles: Gloss, color changes. Construction and Building Materials. 2015. vol. 102, pp. 416- 421.

[7] FRANCESHI, E., GIORGI, M., LUCIANO, G., PALAZZI, D. and PICCARDI, E. Archaeometallurgical characterisation of two small copper-based statues from the Cividale Museum (Friuli, Italy). Journal of Cultural Heritage. 2004. vol. 52, pp. 205-211.

[8] FRANCESHI, E., LETARDI, P. and LUCIANO, G. Colour measurement on patinas and coating system for outdoor bronze monuments. Journal of Cultural Heritage. 2006. vol. 7, pp. 166-170.

[9] VERDINGOVAS, V., JELLESEN, M. S. and AMBAT, R. Colorimetric visualization of tin corrosion: A method for early stage corrosion detection on printed circuit boards. Microelectronics Reliability. 2017. vol. 73, pp. 158-166.

[10] BENZONELLI, A., FREESTONE, I. C. and MARTINON-TORRES, M. A better shade of black: Effects of manufacturing parameters on the development of ancient black bronzes. Archaeometry. 2017. vol. 59, no. 6, pp. 1034-1049.

[11] ROBBIOLA, L., QUEIXALOS, I., ZWICK, A., BASLÉ, K., DANIEL, F., DRIEUX-DAGUERREF, M., DUCOMG, P. J. F. and FRITSCHG, J., Disinfestation of historical buildings - corrosion evaluation of four fumigants on standard metals. Journal of Cultural Heritage. 2015. vol. 16, pp. 15-25.

[12] CHANG, T., HERTING, G., GOIDANICH, S., SÁNCHEZ AMAYA, J.M., ARENAS, M.A., BOZEC, N. LE, JIN, Y., LEYGRAF, C. and ODNEVALL WALLINDER, I. The role of Sn on the long-term atmospheric corrosion of binary Cu-Sn bronze alloys in architecture. Corrosion Science. 2019. vol. 149, pp. 54-67

[13] CHANG, T., HERTING, G., JIN, Y., LEYGRAFB, C. and ODNEVALL WALLINDER I. The golden alloy Cu5Zn5Al1Sn: Patina evolution in chloride-containing atmospheres. Corrosion Science. 2018. vol. 133, pp. 190203.

[14] KIEGLE--BÖSKLER, G. Color and Appearance. STREIBERGER H.-J., DÖSSEL, K.-F. Automotive Paints and Coatings, Second Completely Revised and Extended Edition. Weinheim. Wiley-VCH Verlag. 2008. chapter 12.1. pp. 381-405.

[15] GROSSMAN, A. Identification of Corrosion Products According to Their Colors. GROSSMAN, A. Corrosion for Everybody. Springer, New York. 2010. Appendix I. pp. 333.

[16] KUHN H. Neue Reinigungsmethode für korrodierte Bleigegenstande. Museumskunde. 1960. vol. 29, pp.156-161.

[17] COSTA, V. and URBAN, F. Lead and Its Alloys: Metallurgy, Deterioration and Conservation, Studies in Conservation, 2005. vol. 50, no. 6, pp. 48-62.

[18] VOJTĚCH, Dalibor. Konzervování a restaurování olova a jeho slitin. Technical museum in Brno - Metodické centrum konzervace. Konzervování a restaurování kovů. Brno: Technické muzeum v Brně. 2011. chapter 7.6.1, pp. 537-542. In Czech.

[19] ADRIEAENS, Annemie and SCHOTTE, Bart. Treatment of corroded lead artefacts. An overview. In: Studies in Conservation, 2006, vol. 51, no. 4, pp. 297-304. 
[20] ISO/CIE 11664-1:2019(E) Colorimetry - Part 1: CIE standard colorimetric observers. 2019.

[21] ISO 11664-2:2007(E)/CIE S 014-2/E:2006 Colorimetry - Part 2: CIE Standard Illuminants for Colorimetry. 2019.

[22] ISO/CIE 11664-3:2019(E) Colorimetry - Part 3: CIE tristimulus values. 2019.

[23] ISO/CIE 11664-4:2019(E) Colorimetry - Part 4: CIE 1976 L*a*b* colour space. 2019.

[24] ISO/CIE 11664-5:2016(E) Colorimetry - Part 5: CIE 1976 L*$^{*} u^{*} v^{*}$ colour space and ' ', v' uniform chromaticity scale diagram, 2019.

[25] SMITH, T. and GUILD, J. The C.I.E. colorimetric standards and their use. Transactions of the Optical Society. 1932. vol. 33, no. 3. pp. 73-134. doi:10.1088/1475-4878/33/3/301.

[26] NYSTROM, D., Colorimetric and multispectra image acquisition, Linkoping University, Istitute of technologies. 2006.

[27] VOLZ, H. G., Industrial colour testing. Fundamentals and techniques, Wiley-VCH publication. 2001.

[28] LUKAC, R. and PLATANIOTIS, K. N. Color Spaces, Color Image Processing: Methods and Application. CRC Press. 2006. chapter 1, pp. 1-45.

[29] SIMONOT, L., HÉBERT, M. and DUPRAZ, D. Goniocolorimetry: From measurement to representation in CIELAB color space. Color Research and Application. 2011. vol. 36, no 3, pp. 169-178. 